\title{
Data Analytics Application: A Case Study of Online Business for Vietnamese Handicraft Products on Amazon
}

\author{
Lan Nguyen Thi Thao ${ }^{1,3}$, Phuong Nguyen Pham Anh ${ }^{1,3}$, Trang Nguyen Thi My ${ }^{1,3}$, Huong Pham Thi \\ $\mathrm{My}^{1,3}$, An Nguyen Thu ${ }^{1,3}$, Le Hoanh-Su ${ }^{2,3^{*}}$
}

\begin{abstract}
The paper is based on data collected from the Amazon website (specific in the Handmade's Category) to understand and analyze Vietnamese artisans' business context. Data analysis is also applied to determine the factors that bring success Handmade products and compare products of the same industry among competitors to find out potential products. By collecting data from Amazon and analyzing the data, we extracted useful information for online business developers. Besides, the list of potential products in Handmade sector can be referred to improve the business and compete with competitors. This paper also proposes solutions to help Vietnamese products become more appealing to international customers on the Amazon website.
\end{abstract}

Key Words: Vietnam Handmade Product, Amazon, Sentiment Analysis, Marketing Strategy, E-Commerce.

\section{INTRODUCTION}

Handicrafts are considered a Vietnamese cultural heritage that brings many economic, cultural, and social values. Handicrafts are mostly from craft villages in rural areas and are made by artists in the handicraft village. Vietnam currently has nearly 2,000 trade villages, 115 product categories, about 1.4 million households and 1,000 businesses engaged in production and export. However, influenced by the modern society, trade villages face the risk of gradual disappearance due to the narrowing of the domestic market, the difficulty in consuming products, the low price and the low economic efficiency resulting in the lack of human resources. Under the impact of international economic integration, many importers have been present in Vietnam, playing a significant role in the export of Vietnam's handicraft products to other countries in the world [1]. Vietnam's handicrafts are exported to 163 countries and territories, including the US, Japan, and the
EU. Also, there are cooperation links with major retail groups in the world such as Carrefour (France), Nitori (Japan), and agents seeking large sources of goods such as Li \& Fung (Hong Kong), which are currently the leading supply chain for Walmart, Target [2].

Because of the difficulties in exporting in the traditional form, a new way for Vietnam's handicraft export is CrossBorder E-Commerce. According to retail sales statistics, global e-commerce reported having an $18.5 \%$ increase in 2019 , reaching an estimated level of $22 \%$ of total sales in 2020. It shows that cross-border e-commerce is becoming a vital export channel [3]. Amazon is one of the largest ecommerce platforms globally, with more than 300 million shoppers from 185 countries and 18 websites. Through Amazon, Vietnamese handicraft products have the opportunity to directly access this massive number of customers so that businesses can easily reach customers, expand markets and search for information. However, the number of Handmade Vietnamese products on Amazon is

\footnotetext{
Manuscript received December 06, 2020; Revised January 21, 2021; Accepted February 01, 2021. (ID No. JMIS-20M-12-038) Corresponding Author $\left(^{*}\right)$ : Le Hoanh-Su, University of Economics and Law, Ho Chi Minh City, Vietnam, +84909 511660 , sulh@uel.edu.vn.

${ }^{1}$ Research Assistant, Department of E-commerce, University of Economics and Law, Ho Chi Minh City, Vienam, \{lanntt17411c, phuongnpa17411c, trangntm17411c, huongptm17411c, annt17411c\}@st.uel.edu.vn

${ }^{2}$ Dean, Faculty of Information Systems, University of Economics and Law, Ho Chi Minh City, Vietnam, sulh@uel.edu.vn

${ }^{3}$ Vietnam National University Ho Chi Minh City, Vietnam
} 
still limited (about more than 1,000 products). The limitation is because artisans are having some difficulties in product selection, shipping policies, language barrier. By analyzing the data, we find potential products with a competitive advantage over foreign products and solve the common problems that artisans have when approaching Amazon.

\section{RELATED WORKS}

\subsection{Opinion Mining}

Sentiment Analysis (also known as emotional analysis) refers to the use of natural language processing techniques (NLP-Natural Language Processing), text analysis (text analysis), and linguistic learning (computational linguistics and biometrics to systematically judge positive or negative personal feelings or opinions, extract, quantify and study emotional states and subjective information about a topic, or a product/brand. Opinion mining is used in exploring customer's opinion and feedbacks in several industries[4], [5].

\subsection{SentiWordNet}

SentiWordNet is a tool used in opinion extraction based on the WordNet English vocabulary dictionary. Adjectives grouped words and nouns and other parts of speech with words with similar meanings are called Synsets Lists (Synonyms). SentiWordNet scores the words and words to express the sentiments of the test: positive, neutral, negative [6], [7], [8].

In this paper, we use this library to make a positive and negative grading scale for the Review of Handmade products from Vietnam, China, and Amazon Best Sellers.

\subsection{Linear Regression}

"Linear regression" is a statistical method for regressing data with dependent variables having continuous values while independent variables can have either continuous values or classification values. In other words, "Linear regression" is a method to predict the dependent variable (Y) based on the value of the independent variable (X). It can be used for cases where we want to predict a continuous number [9], [10].

In this paper, we use linear regression to calculate the potential points of top-seller products, from which to list the top most potential Handmade products.

\section{PROPOSED METHOD}

The paper uses three main research methods:

- Method of document research

- Learn and choose a research model that influences potential product listings.

- Learn the methods of mining text data.

- Methods of empirical research

- Statistics, data processing collected from amazon.com website.

- Analyzing the data gathered from amazon.com to find the factors that influence the success of a product. From there, propose a list of potential products.

In order to solve the problem as well as carry out the research, the research team conducted an analysis of the business context of Vietnamese, Chinese, and Amazon Best Sellers artisans and measured user emotions through real estate assessment. Products. After researching and giving an overview of Vietnamese, Chinese, and Amazon Best Sellers products, the team built a model of factors affecting the potential of the product to select the product list. Existing potential and propose a new way for the categories that Vietnamese artisans have not exploited on Amazon market. Specifically, the solution and analytical research steps are shown through the following models:.

\subsection{Research Process}

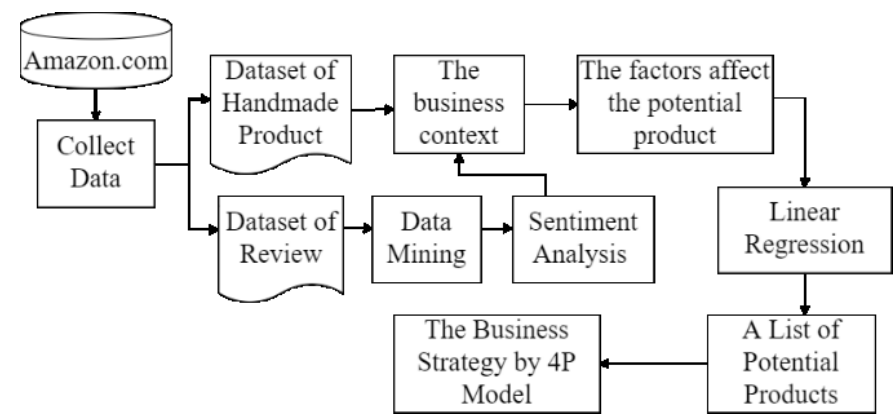

Fig. 1. Research Process.

In order to find out a list of potential products, our team has built a research process by the following:

Collecting data from the Amazon.com website and obtained two datasets: Dataset of Handmade products and Dataset of Review:

- For product data (including Vietnam's Handmade Products, China's Handmade Products, Amazon Best Sellers): Our team conducted statistics to determine Vietnamese artisans' current business context through metrics as product category, prices, estimated net profit. We were simultaneously doing a similar analysis to find out and compare Chinese artisans' business situation, top 50 
Amazon Best Sellers products of sellers in the world with Vietnamese artisans.

- For product review data: Our team conducted sentiment analysis and labeled the reviews to understand the user's feelings about the above products.

From the above studies, our team has modeled the factors affecting product potential based on the book Product Research 101 by Clark R. [11]. Next, and our team applied a linear regression model with the variables (the five factors) that affect a product's potential to score that product's potential. From there, find a list of potential products. Finally, our team built a business strategy for these potential products following the $4 \mathrm{P}$ model based on suggestion by Goi [12].

\subsection{Model of factors affecting the potential of the product:}

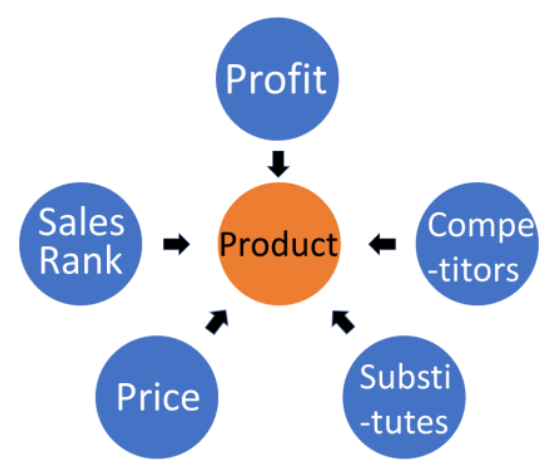

Fig. 2. Model of factors adapted from the book Product Research 101 by Clark, $\mathrm{R}$.

- Sales Rank

Sales Rank has a positive influence on the potential of a product. The lower the sales rank (the small number), the more sales it has.

- Price

Price has a positive effect on product potential. Price is directly proportional to profit.

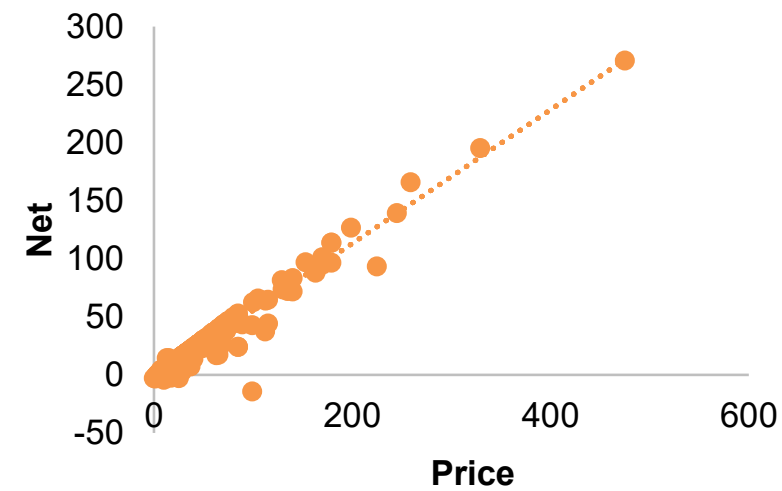

Fig. 3. Describe the relationship between price and profit margin.

- Alternative product
Substitute products have a negative effect on the potential of the product.

- Competitors

Competitors have a negative impact on the potential of the product.

- Profit

Profits have a positive effect on the potential of the product.

\subsection{Solve the problem:}

Step 1: Pre-processing:

According to Clark (2015), the potential of a product is influenced by 5 factors including Sales Rank, Price, Alternative products, Competitors and Profit scores. However, these factors have different units, so we standardize into 0 to $100 \%$ scales as following formular: Standardized equation:

$R_{i}=\left(R_{0 i}-R_{1}\right) /\left(R_{n}-R_{1}\right)$

where as

Ri: value after standardization of each factor score

R0i: value before normalization

$\mathrm{R} 1$ : minimum value of the factor scores

$\mathrm{Rn}$ : maximum value of the factor scores

Step 2: Applying a linear regression model with five factors that affect the potential of the product.

The potential of a product will be presented as:

$Y=b_{0}+b_{1} R_{1}+b_{2} R_{2}+b_{3} R_{3}+b_{4} R_{4}+b_{5} R_{5}$ (2) where as $b_{0}, b_{1}, b_{2}, b_{3}, b_{4}, b_{5}$ are coefficients

So, the higher $\mathrm{Y}$ value is the higher potential of a product.

Step 3: Based on the value of $\mathrm{Y}$, we filtered potential products from the Best Seller product data set.

Input: The target product profiles we choose to handle is in the top $0.5 \%$ of each category, that means five thousand best-selling products out of nearly one million of Amazon's Handmade products.

Output: Top 1,000 most potential products.

Step 4: Filter potential existing products.

Input: Vietnamese products are currently being traded on Amazon Handmade and top 1,000 filterable products in step 3.

Output: List of potential products.

\section{EXPERIMENTAL RESULTS}

4.1. Conclusion of the current business context of 


\section{Vietnamese Artisans:}

Data about product details are collected from Amazon website in the top Sales Rank category. Over 1,243 products, only $31 \%$ of the products are in each category's top Sales Rank. The products lack creative elements, are not diverse, and the main material used is not eco-friendly (such as wood, pure leather). The average price of Vietnamese products is lower than the other Chinese products. That may be the factor that helps Vietnamese products compete with products of Chinese artisans in the same item.

\subsection{Compare the business context between Vietnam and other countries on Amazon:}

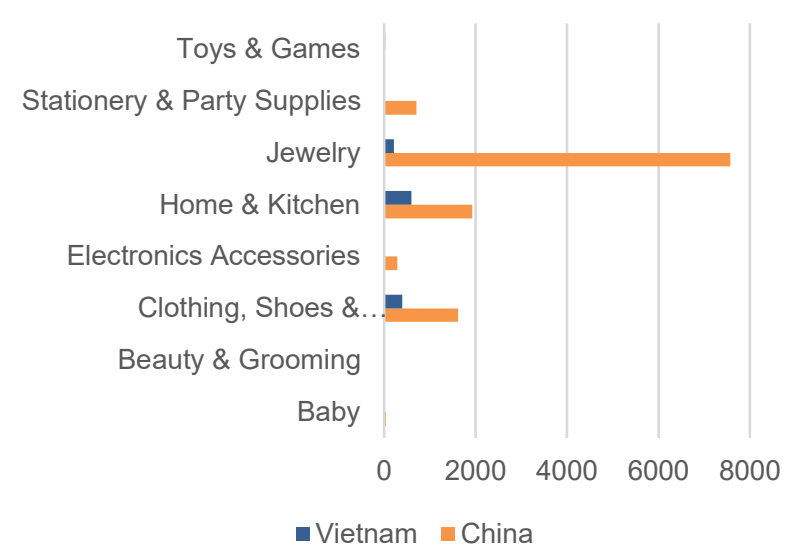

Fig. 4. Compare with China in terms of product quantity by product category.

The flagship category of China is Jewelry, with a quantity of 7,571 products. While in this category, Vietnam has only 218 products. The reason why Chinese artisans focus on this category is that the purchasing power of this jewelry item in the world is enormous (The jewelry industry has the largest number of products of Amazon Best Sellers, accounting for $18 \%$ of the proportion). Besides Jewelry, the Home \& Kitchen category has several Chinese products up to 1,930 products. However, this is the industry that Vietnam is participating in the most, with 594 products. Besides, the demand for products in the Home \& Kitchen industry of the world is also quite generous, accounting for $13.89 \%$ of the proportion.

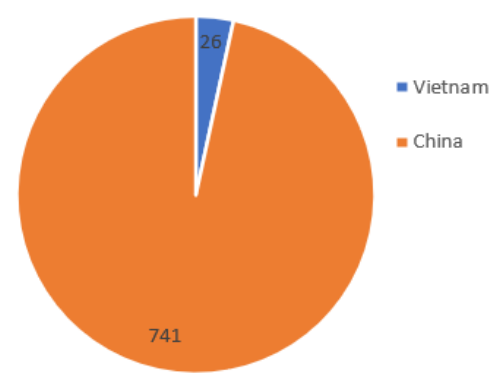

Fig. 5. Compare with China in term of the number of products on top $<25 \%$.

Through the above comparison chart, the number of products in the top $<25 \%$ of China is more than double that of Vietnam. Thereby, it shows that Vietnamese products have not sold much and have not sold well on Amazon. There are some cultural similarities between China and Vietnam, so there will be many similar products. The chart comparing product prices between China and Vietnam shows that Vietnam has a price advantage, so it is possible to consult and explore Chinese products when looking for products sold on Amazon.

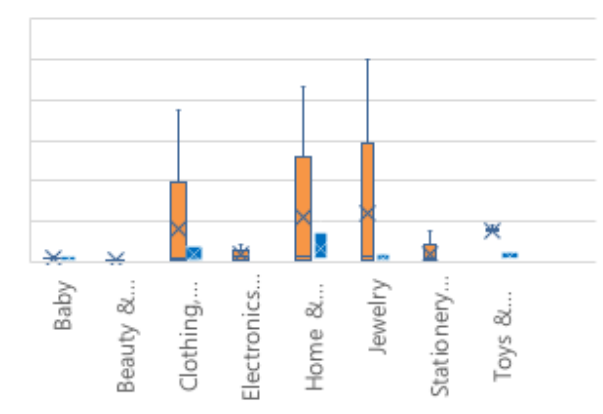

Fig. 6. Compare with China in term of the price range by Category.

The chart shows that most Chinese products' prices are higher than Vietnamese products' prices except for Baby products. The most significant difference is in Clothing, Shoes \& Accessories, Home \& Kitchen, Jewelry. These three categories have the highest product prices in the range of 700 USD - 1000 USD. Vietnamese products only fluctuate in the range of less than USD 100. This shows that Vietnam has a competitive advantage in price compared to Chinese products. 


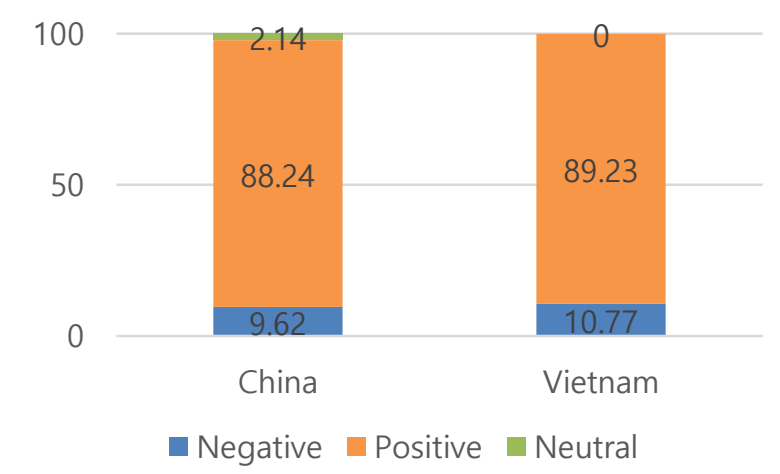

Fig. 7. Compare with China in term of customer emotions about products.

As Vietnamese products receive less attention from customers, with only 58 reviews on more than 1,000 products from the chart above. However, in return, the reviews are positive to show customer satisfaction when buying products. Meanwhile, there are more than 2,000 reviews for Chinese products, with about $80 \%$ positive reviews and 211 (account for 10.55\%) negative reviews. This shows that Chinese products are interested by international customers.

\subsection{Propose the potential category:}

Table 1 . The potential category.

\begin{tabular}{|c|c|}
\hline Category & Reasons \\
\hline \multicolumn{2}{|c|}{ From Amazon Best Sellers } \\
\hline Sports \& Outdoors & $\begin{array}{l}\text { Highest Net Profit: } 21.18 \text { USD } \\
\text { Low Substitutes: } 27 \text { artisans }\end{array}$ \\
\hline Health \& Personal Care & $\begin{array}{l}3^{\text {rd }} \text { highest Net Profit: } 17.15 \text { USD } \\
\text { Low Substitutes: } 109 \text { artisans }\end{array}$ \\
\hline \multicolumn{2}{|l|}{ From China } \\
\hline Jewelry & $\begin{array}{l}\text { Highest Demand: } 18 \% \text { of the total } \\
3,549 \text { products in Amazon Best } \\
\text { Sellers. } \\
\text { Competitive advantage in price } \\
\text { compared to China (VN: } 12.00 \\
\text { USD - } 18.6 \text { USD \& } \\
\text { China: } 18.12 \text { USD - } 501.00 \text { USD) }\end{array}$ \\
\hline $\begin{array}{l}\text { Home \& Kitchen } \\
\text { (Vietnam's current } \\
\text { flagship category) }\end{array}$ & $\begin{array}{l}\text { Low China Products: } 15.85 \% \text { of } \\
\text { the total } 12,178 \text { products. } \\
\text { Price ranges of China product is } \\
\text { high: } \\
38.66 \text { USD }-295.45 \text { USD. }\end{array}$ \\
\hline Toys \& Games & $\begin{array}{l}\text { Low China Products: } 0.11 \% \text { of the } \\
\text { total } 12,178 \text { products. } \\
\text { Price ranges of China product is } \\
\text { high: } \\
149.00 \text { USD - } 185.00 \text { USD. }\end{array}$ \\
\hline
\end{tabular}

\subsection{A list of potential products:}

From the application of the proposed model, the group proposed a potential product list, including:

The list of potential products currently includes 19 products, from Baby categories (Doll, Puppet); Clothing, Shoes \& Accessories (Bag, Hair Pin, Hair Tie, Hat, Keychain, TShirt, Wallet); Home \& Kitchen (Mug, Painting, Pillow cover, Ring Box, Gift Box); Jewelry (Bracelet, Brooch, Headband, Necklace, Ring).

The list of untapped potential products includes 15 products, from 8 Baby categories (Dress, Pacifier); Clothing, Shoes \& Accessories (Briefcase, Hoodie); Electronics Accessories (Phone Case, Stickers); Home \& Kitchen (Art Print, Hanger); Jewelry (Cufflink, Watch); Pet Supplies (Scarf); Stationery \& Party Supplies (Cake Topper, Cup, Poster) and Toys \& Games (Puzzle).

\section{- Peripheral factors affecting the product and sort order:}

After proposing a list of potential products, we conducted further analysis on the list based on a few product selection criteria, including:

(1) User reviews - Rating (star): High user reviews indicate that a product is selling well because they have less than $5 \%$ of buyers leave a review. From this data, it is possible to find quality products that customers are interested in.

(2) Evaluate (count)

(3) Search traffic (count): For online businesses, keyword search is essential to show how much a product is of interest and to determine the level of customer demand for that product.

(4) Availability of materials (\%): materials can be considered a criterion that demonstrates Vietnam's production ability for potential products whose materials are truly suitable to customers' needs.

(5) Weight (lb): Shipping cost to Amazon as well as FBA charge based on weight will be less for soft goods. In addition, in some cases, customers tend to choose small and light products to save delivery costs, so the weight criteria affect the appeal of the product.

(6) Environmentally friendly (amount of product): The issue of environmental protection and human health has been increasingly focused, grasping this consumer psychology, many businesses have chosen to approach customers with products friendly with the environment to create a good impression on the business for customers, to create the image of a brand that not only has right products but also protects the natural environment, drives consumer healthily and safely.

\section{- Analysis results:}

A list of products with high search traffic, reviews, and 
material availability, including six existing products and three unexploited products:

\section{Product:}

Business model for Handmade: This is a model of the seller who makes or creates his product for sale on Amazon. According to the report "The State of the Amazon Seller in 2020 " by Jungle Scout Handmade, the business model has the highest profit margin, with the proportion of $28 \%$ of artisans having a profit margin of over $25 \%$. Vietnamese artisans should choose the Handmade model over other models because when participating in Amazon Handmade, artisans will be creating a free store instead of $\$ 39.99$ per month for a seller on Amazon.com.

Recommended products: Potential product groups with high search traffic, reviews, and material availability come from Clothing, Shoes \& Accessories (Bag, Keychain, Wallet); Home \& Kitchen (Mug); Jewelry (Headband, Necklace); Baby (Dress); Electronics Accessories (Phone Case); Toys \& Games (Puzzle).

\subsection{Business Strategy for product groups by the $4 P$ model}

Create an optional Product Package (Bundle): The Bundle includes highly complementary items, which means that items in the same package complement each other and increase the use of other items in the package or bring convenience to users when they buy them together. When selling a single product, artisans face stiff competition from other brands that sell similar items. The product package is the solution to this problem because it is a combination of many items that are often purchased together (refer to Frequently Bought Together suggested by Amazon). Artisans can customize packages your products are unique to have Buy Box. Artisans should consider choosing a Bundle for the benefits after:

- On the customer's side: Product packages create real value for buyers when they buy what they need at a discounted price and save time instead of buying each product.

- From the artist side: By combining products into one product package, artisans can sell low-seller products with their best-seller to sell more products. In addition, FBA fees are only charged on one item (package of products) instead of each item, so artisans will be able to make a higher profit and avoid competing with similar products than sell each product individually.
Table 2. A list of products.

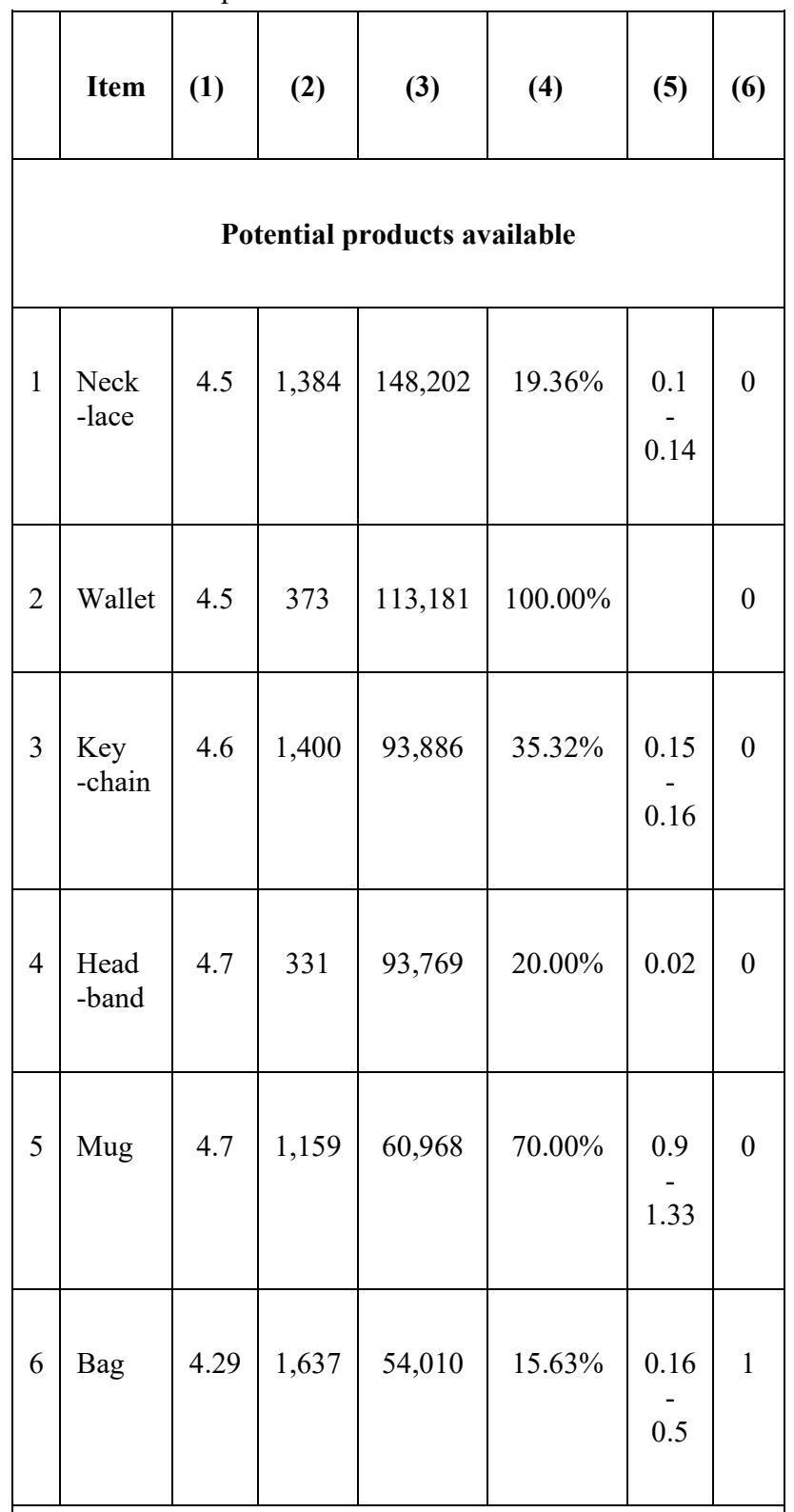

Potential unexploited products

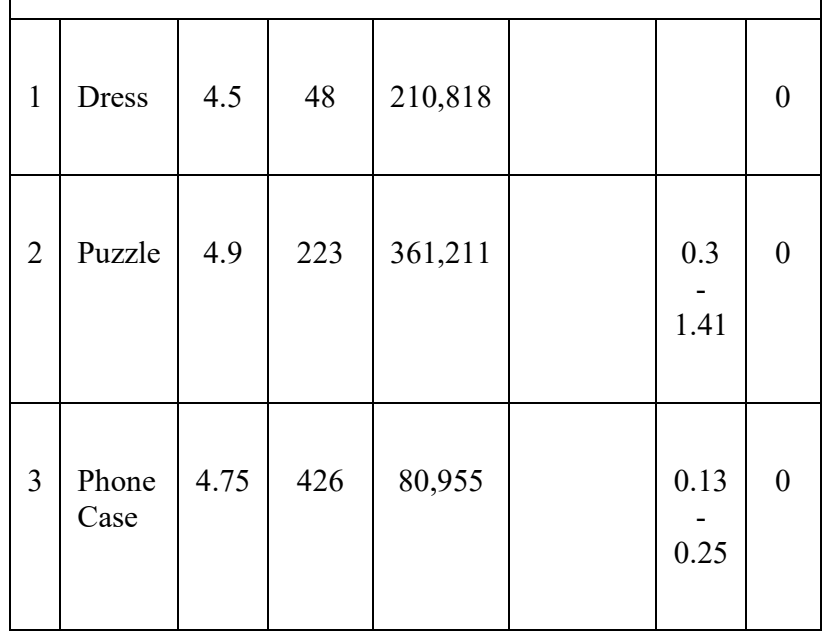


Get the Buy Box: According to statistics, Amazon generates more than $\$ 250$ billion in revenue each year, $80 \%$ from Buy Box usage. Buy Box stimulates buying demand and customers just click Buy Now to go to Shipping \& Payment without considering anything else, and with add to cart, customers have to review selected products at this time. Other proposed products may change customers' minds. Winning a Buy box is very important. Customers will have confidence in high products, exclusive products, and fast sales.

Appropriate price changes: When launching new products or large holidays, can afford a reduced price to attract customers, increase sales. However, it must be calculated carefully that the price reduction does not differ too much, leading to no profit and when returning to the original price, the value of the product is reduced.

Psychological pricing, customers: Through data collection, the prices of products are not rounded but odd numbers like $\$ 9.99, \$ 29$. These prices are based on customer psychology, though not much different than rounding, but customers still feel cheaper. Hitting the customer's emotional side gives them an illusion of added value.

Catch the target audience through demand research, demographic analysis (age, gender, income, status), behavior (search for handicraft products, relatives environmental friendly, unique, personalized).

\section{Promotion}

Amazon Ads: Amazon Marketing Services is a marketing system that allows merchants to run ads on the Amazon platform to help them reach more customers, grow sales, and grow their brand. Amazon Marketing Services includes three advertising forms: Headline Search Ads (Sponsored Ads), Sponsored Products Ads, and Product Display Ads. Sellers can choose one of three types depending on the purpose of the advertising campaign that the seller toward and the amount of budget they are willing to pay to get an advantage.

Brand development on social media channels: YouTube Channel, Facebook, Pinterest, Instagram.

Deals: Creating promotions for a certain period will help attract customers and help them make decisions quickly, thereby increasing their revenue.

Place: Amazon Handmade

\section{CONCLUSION AND FUTURE WORKS}

Through collected data and an overview of handmade products in Vietnam, China, and Amazon Best Sellers, this paper finds out the factors affecting the potential development of Handmade products on the Amazon market. List of potential existing products and new ways for selecting categories that Vietnamese artisans have not yet exploited on Amazon is proposed for handmade suppliers. In addition, 4P strategy for development business with handmade products has been proposed, business developer can take references to utilize the business platform of Amazon.

In the future research direction, we will not only collect data on Amazon, but also collect data of products on social networking sites Facebook, Twitter and other e-commerce sites in the world to conduct cross reference research. We should also analyze the features prompted in the review to improve the products and services offered on Amazon as suggested by Le [13].

Acknowledgement

This research is funded by the University of Economics and Law, Vietnam National University Ho Chi Minh City, Vietnam.

\section{REFERENCES}

[1] Hitchcock, Michael, T. T. H. Nguyen and Simone Wesner. "Handicraft heritage and development in Hai Duong, Vietnam," Heritage tourism in Southeast Asia, pp. 221-235, 2010.

[2] Gough Katherine V. and Jonathan Rigg, "Reterritorialising rural handicrafts in Thailand and Vietnam: a view from the margins of the miracle," Environment and Planning, vol. 44, no.1, pp. 169-186, 2012.

[3] Vietcraft.org.vn. (2020). Vietnam Handicraft Exporter Association, Retrieved 20/02/2020

[4] Hoanhsu Le, Jonghwa Lee, and Hyun-Kyu Lee, "Purchase Process Aspect-based Opinion Mining: An Application for Online Shopping Mall," The Journal of Internet Electronic Commerce Research, vol. 15, no. 2, pp. 15-28, 2015

[5] Jun-Ho Huh, Sugarbayar Otgonchimeg, Kyungryong Seo, "Advanced metering infrastructure design and test bed experiment using intelligent agents: focusing on the PLC network base technology for Smart Grid system," The Journal of Supercomputing, vol. 72, no. 5, pp. 1862-1877, 2016.

[6] Jun-Ho Huh, Kyungryong Seo, "Development of competency-oriented social multimedia computer 
network curriculum," Journal of Multimedia Information System, vol. 1, no. 2, pp. 133-142, 2014.

[7] Esuli, Andrea, and Fabrizio Sebastiani, "Sentiwordnet: A publicly available lexical resource for opinion mining," LREC, vol. 6, pp. 417-422, 2006.

[8] Godsay M., "The Process of Sentiment Analysis: A Study," International Journal of Computer Applications, vol. 126, no. 7, pp.26-30, 2015.

[9] Uyanık, Gülden Kaya and Neşe Güler, "A study on multiple linear regression analysis," Procedia-Social and Behavioral Sciences, vol. 106, pp. 234-240, 2013.

[10] Montgomery, Douglas C., Elizabeth A. Peck and G. Geoffrey Vining, Introduction to linear regression analysis, vol. 821, John Wiley \& Sons, 2012.

[11] R. Clark, Product Research 101: Find Winning Products to Sell on Amazon and Beyond, Dilettante Living Press, 1st Edition, 2015

[12] Goi Chai Lee, "A review of marketing mix: 4Ps or more," International journal of marketing studies, vol. 1, no. 1, pp. 2-15, 2009.

[13] Hoanh Su Le, Cuong Trieu, Thanh Ho, Jong-Hwa Lee, Hyun-Kyu Lee, “Applying Artificial Neural Network for Sentiment Analytics of Social Media Text Data in fastfood industry," The Journal of Internet Electronic Commerce Research, vol. 17, no. 5, pp. 113-123, 2017.

Authors

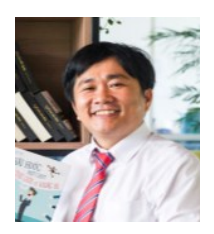

Le Hoanh-Su received the B.E in Electronics and Telecommunication, MSc in MIS and MBA degrees from Vietnam National University HCM City in 2013, the Ph.D. degrees in E-business from Pukyong National University, South Korea. From 2006 to 2011, he was Senior Engineer, Project Team Leader at Global CyberSoft and since 2011 he has been a faculty member, and currently Dean of School of Information Systems at University of Economics and Law-VNUHCM. His research interests are in the areas of data analytics, big data, robotics and AI.

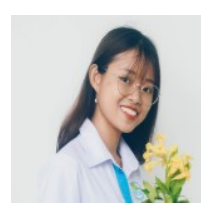

Lan Nguyen Thi Thao was born in Ho Chi Minh City, Republic of Vietnam. In Aug. 2017, she became a student at the University of Economics and Law, VNU-HCM, Department of E-commerce. Her research interests include e-commerce market, payment market.

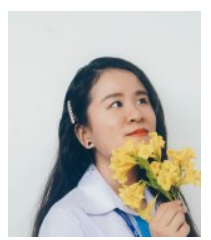

Phuong Nguyen Pham Anh was born in Ho Chi Minh City, Republic of Vietnam. In Aug. 2017, she became a student at the University of Economics and Law, VNUHCM, Department of E-commerce.

Her research interests include e-commerce market, payment market.

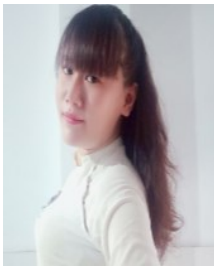

Trang Nguyen Thi My was born in Ho Chi Minh City, Republic of Vietnam. In Aug. 2017, she became a student at the University of Economics and Law, VNUHCM, Department of E-commerce.

Her research interests include ecommerce market, payment market.

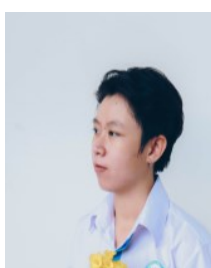

Huong Pham Thi My was born in Ho Chi Minh City, Republic of Vietnam. In Aug. 2017, she became a student at the University of Economics and Law, VNUHCM, Department of E-commerce.

Her research interests include ecommerce market, payment market.

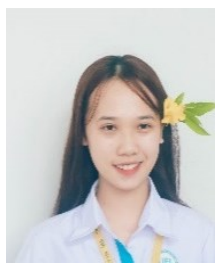

An Nguyen Thu was born in Ho Chi Minh City, Republic of Vietnam. In Aug. 2017, she became a student at the University of Economics and Law, VNU-HCM, Department of E-commerce.

Her research interests include e-commerce market, payment market. 